\title{
Fiber endoscopy for the Diagnosis and Treatment of Congenital Esophageal Hypertrophic Stenosis of Infants
}

\author{
Xue Qi Wang ${ }^{1,2}$, Chi Huan Kong ${ }^{1}$, An Xiao Ming ${ }^{1}$, Ye Tong Wang ${ }^{1}$ and Long Li ${ }^{1,2 *}$ \\ ${ }^{1}$ Capital Institute of Pediatrics, Beijing, China \\ ${ }^{2}$ Graduate School of Peking Union Medical College, China \\ *Corresponding author: Long Li, Capital Institute of Pediatrics, Beijing, 100020, China
}

\section{ARTICLE INFO}

Received: 幽 November 25, 2019

Published: 仹 December 02, 2019

Citation: Xue Qi Wang, Chi Huan Kong, An Xiao Ming, Ye Tong Wang, Long Li. Fiber endoscopy for the Diagnosis and Treatment of Congenital Esophageal Hypertrophic Stenosis of Infants. Biomed J Sci \& Tech Res 23(3)-2019. BJSTR. MS.ID.003900.

Abbreviations: CEHS: Congenital Esophageal Hypertrophic Stenosis; EMH: Esophageal Muscular Hypertrophy; TBR: Tracheobronchial Remnant; FMH: Fibromuscular Hypertrophy; MD: Membranous Diaphragm

\section{ABSTRACT}

Objective: To investigate the diagnosis and effect for the treatment of CEHS of infant with endoscopy.

Methods: To summarize and review the data of 5 cases of CEHS during Apr. 2017 to Jan. 2018. All patients were retrospect the clinical procedures and follow-ups who were carried out examination, diagnosis and treatment with endoscopy and endoscopic ultrasonography in the middle and lower parts of esophagus.

Result: The characters of esophageal stenosis in infants could be identified using endoscopy and endoscopic ultrasonography. For the muscular hypertrophic stenosis, the narrow parts could be successfully relieved to $12-15 \mathrm{~mm}$ in diameter by using endoscopic balloon dilatation.

Conclusion: It is feasible to use endoscopy for the diagnosis and treatment of CEHS occurred in the lower part of esophagus in infants. Excessive damages and occurrence of restenosis after traditional esophagectomy could be avoided.

Keywords: Infant; CEHS; Endoscopic Ultrasonography; Muscular Hypertrophy; Balloon Dilatation

\section{Introduction}

Most of the CEHS in infants and young children are benign stenosis causing difficulty in eating, vomiting, aspiration, and developmental retardation, etc. and electrolyte imbalance in severe cases. Previously, the obstruction was to be relieved by esophagectomy and re-anastomosis, and the nature of stenosis be distinguished by postoperative pathology. In the past two years, with the assistance of electronic endoscopy and endoscopic ultrasonography, a successful approach for the diagnosis and treatment of stenosis caused by EMH has been achieved.

\section{Materials and Methods}

\section{Clinical Information}

During Apr. 2017 to Jan. 2018, a total of 5 cases, 2 males, 3 females, of hypertrophic stenosis of the lower esophagus were found. One of them had been cured due to congenital esophageal atresia. The age of visiting was 1 year and 1 month to 2 years and 7 months old, and the first onset occurred 4-7 months after birth, when the initial stage of food supplementation was added. The age of visiting was 9-14 months later behind the onset time, and the weight of visiting was $7.7-12 \mathrm{~kg}$

\section{Methods}

\section{Imaging Examination}

All cases were undergone upper gastrointestinal radiography. To avoid the inhalation of barium into the lungs, Iohexol injection was used orally for radiography (Figures 1-4). The later the treatment, the lower the stenosis position, and the more obvious the dilatation of the upper esophagus. 

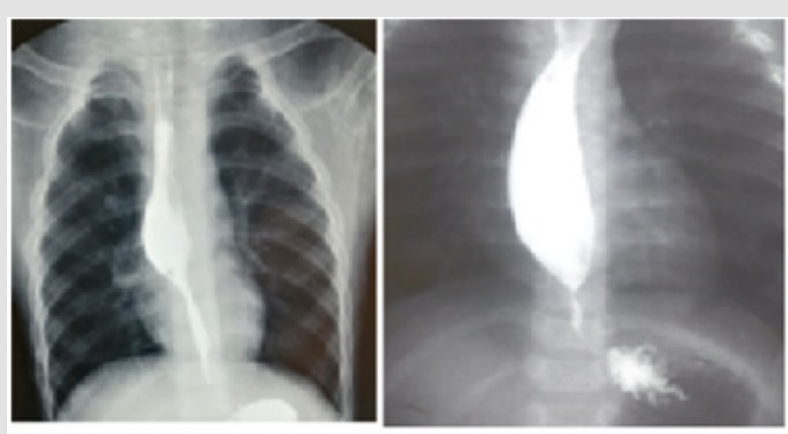

Figure 1

Figure 2
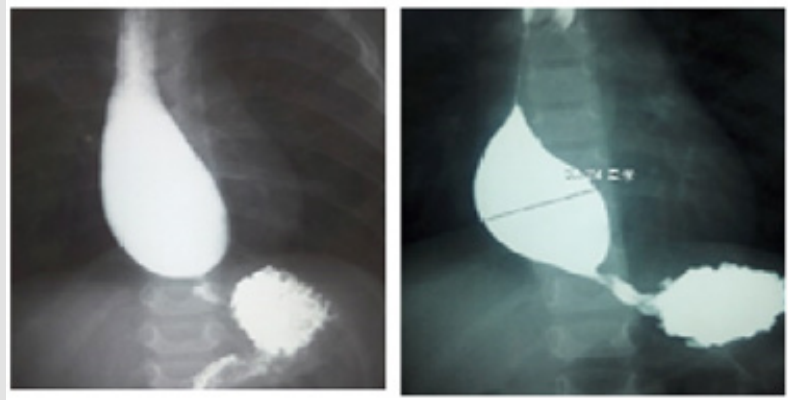

Figure 3

Figure 4

Figure 1-4: Imaging examination of congenital esophageal stenosis.

\section{Endoscopy}

All patients were undergone endoscopy under general anesthesia and endotracheal intubation using FUJIFILM common gastroscope EG-600 and endoscopic ultrasound SP-702. When the gastroscope entered the lower part of esophagus, it was clear that the distribution of esophageal mucosa and vascular network in the place of stenosis was normal. Although the gastroscope with a front end $9 \mathrm{~mm}$ or more in diameter could not enter the stomach through the narrow ring, the stenosis could be slightly opened after peristalsis or gas injection with or without cervix-like bulge at the narrow hole, and the distal end of esophagus or cardiac orifice could be seen from the narrow hole (Figures 5-8).
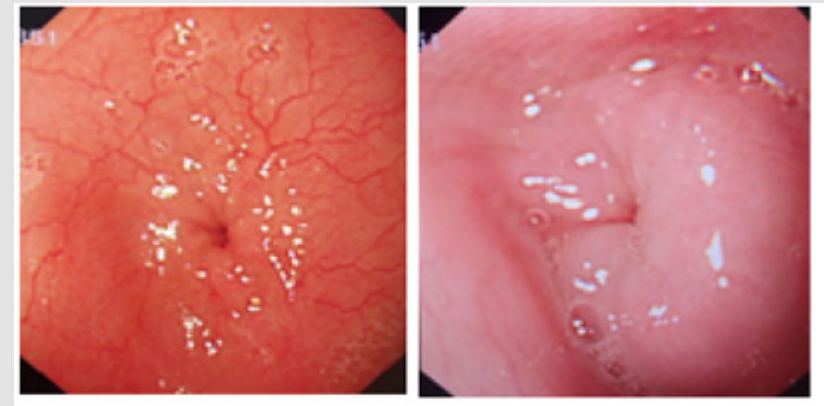

\section{Figure 5}

Figure 6
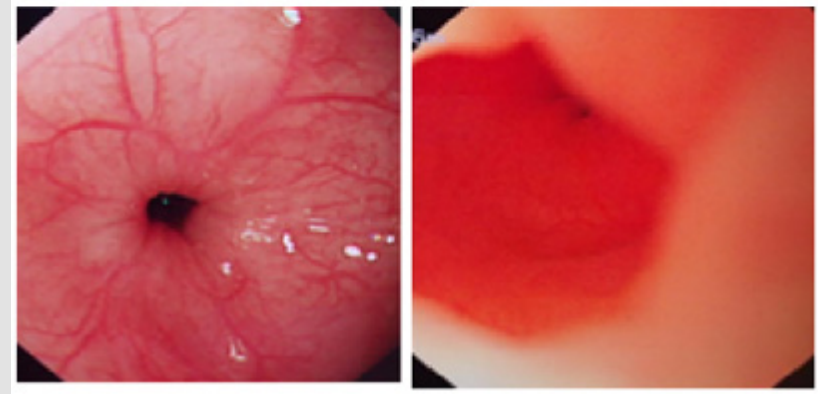

Figure 7

Figure 8

Figure 5-8: Endoscopy of Congenital Esophageal Muscular Hypertrophic Stenosis. 


\section{Endoscopic Ultrasonography}

Endoscopic ultrasonography was performed after the esophagus was infused with sterile water for injection. Endoscopic ultrasound at $20 \mathrm{~Hz}$ could fully display the five layers of the esophageal wall, and it could be found the thickening of the muscularis propria at the place of esophageal stenosis, and the muscle layer seemed to have stratification (Figures 9-11).
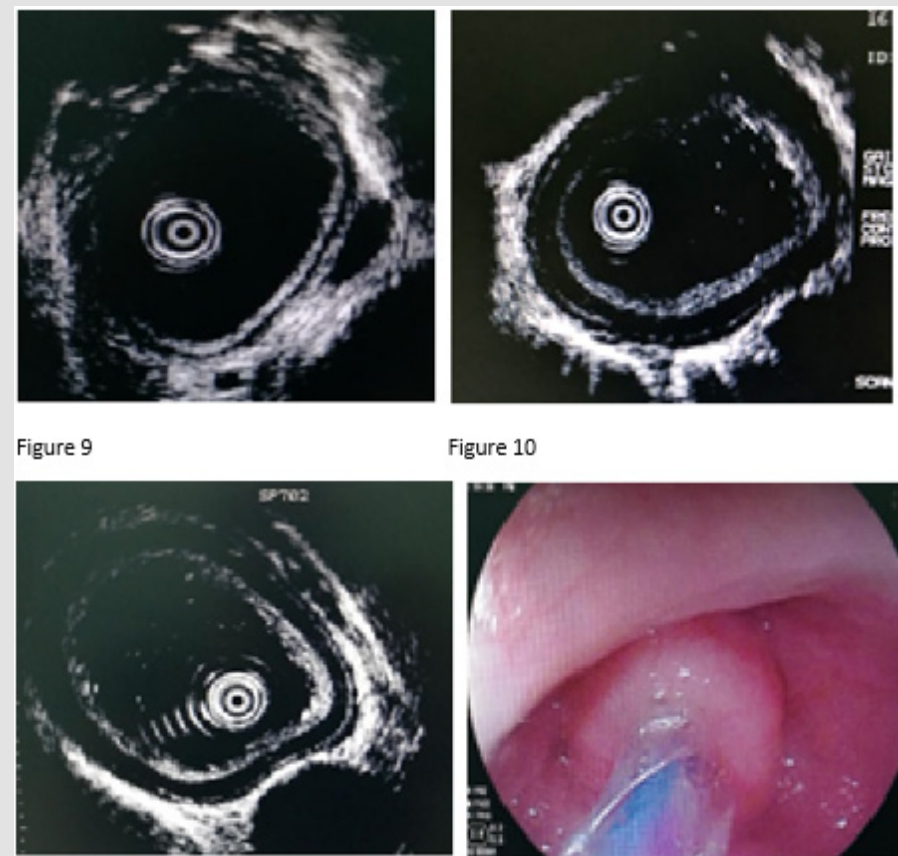

Figure 10

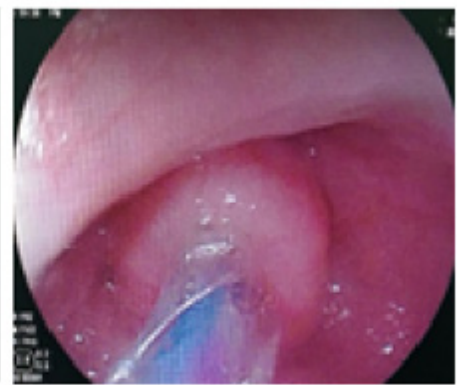

Figure 11

Figure 12

Figure 9-12: Endoscopic ultrasonography of Congenital Esophageal Muscular Hypertrophic Stenosis.

\section{Endoscopic Balloon Dilation}

The endoscopic biopsy channel was introduced into Boston's GRE dilatation balloon for expansion. At the beginning of the balloon passing through the stenosis part or trying pressure expansion, it could be seen that the narrow hole had a ring-shaped "hoop" or " 0 "like bulge (Figure 12), which could even move as the balloon moved up and down (Figure 13). The pressurization was carried out slowly. For each time to increase the pressure value, it was carried out according to the repeated steps of pressurizing, withdrawing the pressure, withdrawing the balloon, and observing the wound surface (Figure 14). The endpoint of dilation was to make the hole to reach $12-15 \mathrm{~mm}$ in diameter or the shallow ring laceration (Figure 15) and to permit the normal gastroscope passing through. After observing without perforation, the treatment could be terminated, and the effect be reviewed one month later.

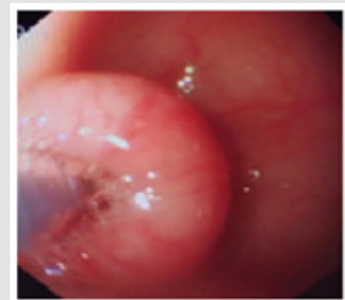

Figure 13

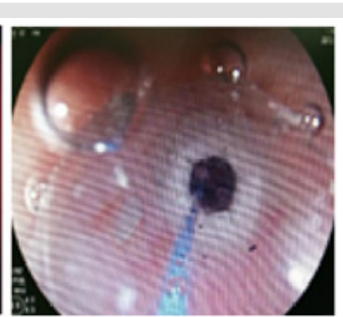

Figure 14

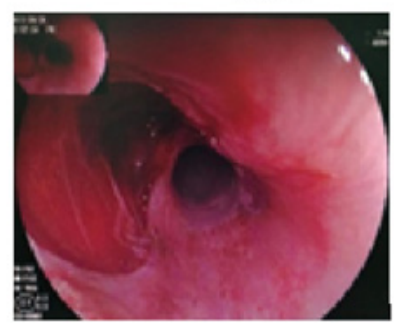

Figure 15

Figure 13-15: Endoscopic balloon dilation treatment. 


\section{Result}

There were not esophageal perforation and no trans surgical surgery among these five patients. One month after the operation, it was reviewed by endoscopy that the stenosis was widened, transforming the " 0 "-like structure to " $\mathrm{C}$ " type (Figure 16). There was no obvious scar on the mucosa, and the ordinary gastroscope could pass smoothly.

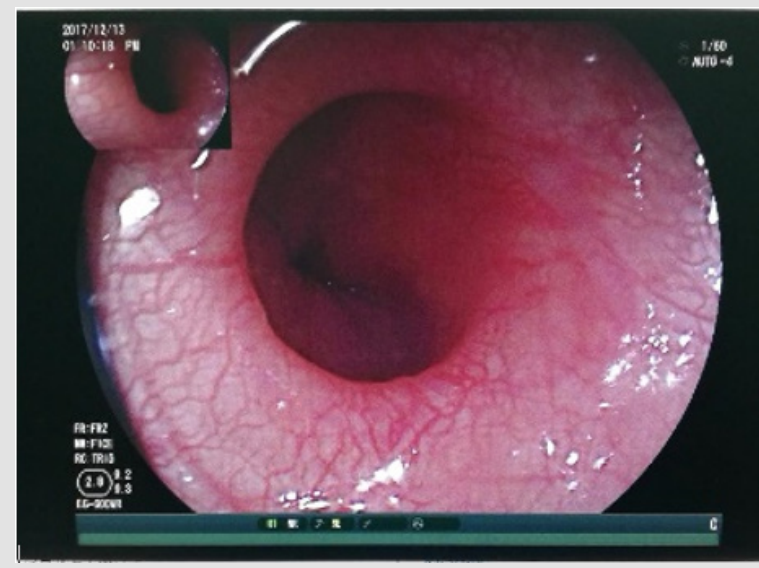

Figure 16: Widened Stenosis, transforming the "O"-like structure to " $\mathrm{C}$ " type.

\section{Discussion}

CEHS is a common esophageal benign disease in infants and young children with the incidence rate of about 1/25000-1/50000 live births. It can be classified into three types according to the results of postoperative pathological examination: TBR, FMH, and MD [1]. By means of upper gastrointestinal angiography and gastroscopy, it is easy to identify and treat MD or esophageal fistula, while preoperative diagnosis of TBR and FMH is indistinguishable, which need to be identified by surgical resection and postoperative pathology [2,3]. The age of the visit and the time of the diagnosis varied depending on the severity of the stenosis and consciousness of parents. Most of the cases didn't visit the hospital until electrolyte disorder occurred, although the symptoms emerged, and unfortunately ignored, when changing the diet structure (such as adding complementary food) [4]. One of the children in this group was after the operation of esophageal atresia. During the operation, it had been found that the 8th gastric tube could not reach the stomach through the distal esophagus, and the 6th gastric tube could.

Thus, the esophageal atresia was ignored, and the lower esophageal stenosis was confirmed by angiography 8 months later. From the results of the upper gastrointestinal contrast, it can be found that the location of the early esophageal stenosis was relatively high, closer to the middle part of the esophagus, and the location of the late esophageal stenosis was found to be lower, closer to the cardia. Similarly, in terms of the proximal extension, it was not found in the cases of early esophageal stenosis, but significant dilation among late cases not only in diameter of reaching more than $30 \mathrm{~mm}$, but also the whole esophagus shape changing into
"C" type. These suggest that esophageal stenosis is a continuous process. It is inaccurate to judge the nature of the stenosis by simply relying on upper gastrointestinal contrast and gastroscope to find the position of esophageal stenosis. It has been reported that endoscopic ultrasonography can accurately and clearly show the hierarchical structure and extra-wall conditions of the digestive tract wall, as well as determine the origin, extent, size and nature of the submucosal lesions, which was of guiding significant for further treatment [5].

In order to ensure a clear diagnosis before surgery, and to avoid the trauma and postoperative complications of surgery performed through the sterile surgical area (thoracic, abdominal cavity), we used common gastroscopic and endoscopic ultrasonography to distinguish the nature of esophageal stenosis and tried to use endoscopic treatment instead of surgical resection. First, we tried to pass the narrow section using electronic gastroscope EG-600WR. When the gastroscope entered the lower part of esophagus, it can be seen that the distribution of esophageal mucosa and vascular network in the place of stenosis was normal. The narrow mouth of the esophagus remains naturally closed. Although the gastroscope with a front end $9 \mathrm{~mm}$ or more in diameter cannot enter the stomach through the narrow ring, the naturally closed narrow mouth can be peristalsis with or without cervix-like bulge, and can be slightly opened after gas injection and the distal end of esophagus or cardiac orifice can be seen from the narrow hole. This confirms that the stenosis has nothing to do with the cardia, nor is it caused by acid reflux. Second, we used endoscopic ultrasonography to observe the 5-layer structure of the esophageal wall [6].

Normal adult esophageal thickness is about $3 \mathrm{~mm}$ [6]. We performed ultrasonography on 5 children in this group and found that the muscular layer of the stenotic segment was significantly thickened, and the thickness of the intrinsic muscular layer could reach $3 \mathrm{~mm}$. The thicker the muscle layer, the more obvious the esophageal stenosis. And the thickened intrinsic muscle layer itself had stratification with the thick inner layer and the thin outer one. In the past, most of the esophageal stenosis that failed to pass or expand by the gastroscope was surgically resected. The surgical methods were either thoracoscopic or laparoscopic alone or combined [7]. However, most of them must pass through the sterile area (thoracic or abdominal cavity), and there are some postoperative complications, such as anastomotic stenosis, gastroesophageal reflux, diaphragmatic eventration [8] and so on. In recent years, there have been reports of endoscopic treatment of lower esophageal stenosis through natural passages $[9,10]$, which avoid some postoperative complications and shorten the hospital stay. We also tried endoscopic treatment instead of surgical resection based on ultrasound results. Endoscopic balloon dilatation is preferred.

The principle of balloon dilation is that the inflated balloon gives a constant, central axis pressure to the stenosis, causing partial tearing of the stenotic muscle layer for expansion [11]. In the first 
3 cases, the target diameter of esophageal dilation was determined to be $11 \mathrm{~mm}$ according to the report [12], and the total expansion was 4-5 times/person. But the effects were still unsatisfactory. With the accumulation of experience, our target diameter was set to $12-15 \mathrm{~mm}$, and the effects were obvious when expanded only 1-2 times/person. It has been reported that the endoscopic expansion target of adults was $15 \mathrm{~mm}$ [12], but the stenosis of children was designed starts to be expanded from $3-5 \mathrm{~mm}$. There would be mucosal, submucosal and muscular damage before reaching to $15 \mathrm{~mm}$. Practically we added the pressure gradually, and for each time to increase the pressure value, damages around the stenosis would be observed and evaluated. The results showed that, when the endoscope with a diameter of $9 \mathrm{~mm}$ or more could pass through the narrow mouth, there would be ineluctable damage to the mucosa, submucosa and part of the muscle layer of the wall. But the surface of damage, if without perforation, was with no need for special treatment, for it was reported that the residue of the anastomotic nail could stimulate the local fibrosis [9].

As the wound ends naturally, the damaged mucosal layer could be naturally apposed and healed after a day or two post operation. On the day after surgery, the case could be given the liquid food and an appropriate anti-inflammatory for 1-3 days and could be discharged 1-2 days after surgery. The review examination one month later showed that the diet structure of the child was significantly improved. The $9 \mathrm{~mm}$ gastroscope could pass through the previous narrow mouth, and the narrow mouth had been transformed from " $\mathrm{O}$ " to " $\mathrm{C}$ ". The one-sided centripetal ring of the wall disappeared. Endoscopic balloon dilatation for the treatment of congenital lower esophageal muscular hypertrophic stenosis in infants is a new minimally invasive surgical treatment, similar to endoscopic treatment of pyloric anterior and duodenal valves $[13,14]$.However, with the auxiliary diagnosis of endoscopic ultrasonography, the wall structure is clearer, which enables us more confident in treatment.

\section{Funding}

This work was supported by Key Pediatrics Project of Pediatric Coordination Development Center, Beijing Hospitals Authority (Grant No XTZD20180302)

\section{Acknowledgement}

The authors are grateful to the involved staff at the hospital for their help and support during fiber endoscopy.

Author Contributions Wang XQ, Kong CH performed the operation, analyzed the data and wrote the paper. Ming AX, Wang
YT performed the operation. Li L designed the project and edited the manuscript. All the authors read and approved the final manuscript.

\section{Conflict of interest}

The authors declare that they have no conflict of interest.

Animal and Human Rights Statement Ethics approval from the Ethics Committee of Capital Institute of Pediatrics was obtained.

\section{References}

1. Nihoul Fékété C, De Backer A, Lortat-Jacob S, Pellerin D (1987) Congential esophageal stenosis: a review of 20 cases. Pediatr Surg Internat 2(2): 8692.

2. Lei HB, Wu C, Pan ZX, Yang JX, Fan Y (2016) Diagnosis and treatment of congenital esophageal stenosis. J Clin Pediatr Surg 15(3): 268-271.

3. Zhong XM, Zhang YL, Li L (2012) Congenital esophageal stenosis owing to ectopic tracheobronchial remnants: report of four cases and review of the literature. Chin J Pediatr 50(8): 571-574.

4. Zhou YX, Mei YQ Yin XQ Liang M, Liu MG (2007) Treatment of congenital esophageal stricture to severe malnutrition and electrolyte disturbance: A case report. Chin J Pediatr Surg 28(4): 207.

5. Liu X, Li RC, Guo JT, Wang S, Ge N, et al. (2016) Diagnostic and therapeutic value of endoscopic ultrasonography for esophageal submucosal lesions. Chin J Digest Endosc 33(5): 287-290.

6. Chen LG, Ren JL (2007) Diagnostic value of endoscopic ultrasonography in disease of esophagus. World Chin J Digest 15(30): 3216-3218.

7. Kong CH, Li L, Diao M, Li Q (2012) Treatment of esophageal stricture in children by combination of thoracoscopy, laparoscopy and electronic gastroscopy. Chin J Pediatr Surg 8: 634-635.

8. Deng PM, Zheng S, Xiao XM (2011) Management of congenital esophageal stenosis: retrospective study of 15 cases. Chin J Pediatr Surg 32(3): 161164.

9. Zhang Z, Zhang YQ Chen WF, Qin WZ, Cai MY, et al. (2016) Endoscopic radial incision in patients with benign stricture of esophageal anastomosis. Chin J Digest Endosc 33(4): 208-210.

10. Hu KF, Ye GL, Jin YP, Guo LH, Qin LJ, et al. (2016) Curative effect of endoscopic push-radial dissection for patients with benign esophageal stricture (with video). Chin J Digest Endosc 33(1): 37-39.

11. Geng LL, Geng ST, Huang H, He WE, Qu WJ, et al. (2008) Balloon dilation with gastroscope for esophageal stricture in children. Chin J Pediatr 46(12): 895-898.

12. Li M, Lin Q, Lian M, Guo HM, Pan J, et al. (2011) Gastroscopic esophagectomy for severe esophageal stricture in children. J Prac Med 27(8): 1443-1445.

13. Kong CH, Li L, Li Q, Dong N, Guan KP (2016) Endoscopic treatment of three cases of congenital anterior pyloric valve. Chin J Digest Endosc 6: 399-400.

14. Kong CH, Li L, Dong N, Li X, Zhang YL (2015) Endoscopic operation in the treatment of congenital duodenal membranous stenosis. Chin J Gastrointest Surg 18(8): 801-803. 
ISSN: 2574-1241

DOI: 10.26717/BJSTR.2019.23.003900

Long Li. Biomed J Sci \& Tech Res

(c) (P) This work is licensed under Creative

Submission Link: https://biomedres.us/submit-manuscript.php

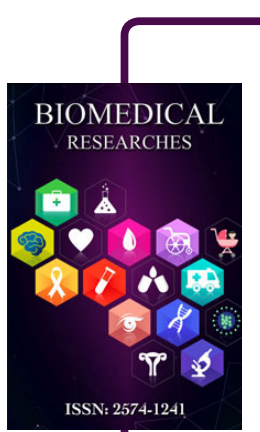

Assets of Publishing with us

- Global archiving of articles

- Immediate, unrestricted online access

- Rigorous Peer Review Process

- Authors Retain Copyrights

- Unique DOI for all articles

https://biomedres.us/ 